\title{
Oxygen consumption calorimetry, William Parker: 2016 DiNenno Prize
}

\author{
C. Beyler ${ }^{1 *} \mathbb{D}$, P. Croce ${ }^{2}$, C. Dubay ${ }^{3}$, P. Johnson ${ }^{4}$ and M. McNamee ${ }^{5}$
}

\begin{abstract}
The 2016 DiNenno Prize recognizes oxygen consumption calorimetry as a significant technical achievement that has had a major impact on public safety. Oxygen consumption calorimetry has made the measurement of heat release rate of a fire a routine part of fire testing for both research and for regulatory compliance. Heat release rate is a primary metric of fire size which is foundational in modern fire protection engineering. The 2016 Philip J. DiNenno Prize is awarded to Dr. William Parker, with ample commendation to his deceased collaborator, Dr. Clayton Huggett. Others who made contributions to the early development and application of oxygen consumption calorimetry include Peter Hinkley, William Christian, Thomas Waterman, Darryl Sensenig, Ralph Krause, Richard Gann, Vyto Babrauskas, Gunnar Heskestad, Norm Alvares, Donald Beason, and Brady Williamson. This review presents an overview of the background to the technological development and its impact on public safety.
\end{abstract}

\section{Introduction}

The DiNenno Prize is intended to recognize "technical achievement that has made a significant impact on public safety...". The development of oxygen consumption calorimetry is the technical achievement recognized by the 2016 Philip J. DiNenno Prize. Oxygen consumption calorimetry (OCC) allows the measurement of the heat release rate (HRR) of a fire by the measurement of the oxygen consumed by the fire.

The concept of oxygen consumption calorimetry was developed in the late 1970's and was quickly adopted for small scale, large scale, and industrial scale applications. The importance of the rate of heat release had been recognized since the late 1950's and several thermal methods had been attempted. However, these methods were difficult to implement and resulted in relatively low measurement accuracy.

The oxygen consumption calorimetry method is based upon the constancy of the heat released per unit oxygen consumed. It requires the collection of all fire effluent in the exhaust, measurement of the exhaust system flow rate, and the oxygen concentration in the exhaust. Since the effluent from fire tests needs to be collected in any laboratory setting, the addition of a flow measurement

* Correspondence: cbeyler@jensenhughes.com

${ }^{1}$ Jensen Hughes, Baltimore, MD 21227, USA

Full list of author information is available at the end of the article and oxygen concentration to existing apparatus was straightforward and relatively easy to implement. The measured heat release rate has been used as a figure of merit for the fire safety of materials or assemblies, and is used as an input to fire models and calculation procedures. Heat release rate measurements by oxygen consumption are utilized in most modern standard fire test methods, and the measurement of heat release rate, as the basis of modelling and analysis of performance based design solutions, is the foundation of modern quantitative fire protection engineering. Oxygen consumption calorimetry ushered in the modern era of fire safety science and engineering.

\section{Technical achievement}

The rate of heat release is the primary scientific description of a fire. It governs the physical size of the fire and the potential to do thermal damage. It relates directly to the generation rate of toxic gases by a fire. The principle of oxygen consumption calorimetry is that the heat release rate can be determined from the oxygen content of the exhaust flow from a hood that collects all the fire products/smoke from a burning item or enclosure. By measuring the exhaust flow rate and the oxygen concentration in the exhaust, the heat release rate can be determined with reasonably good precision.

The first heat release rate method was a thermal compensation method for measuring heat release rate prior 
the development of OCC (Thompson and Cousins 1959). The method was implemented in the FM Roof Calorimeter. Simple temperature and flow measurements in the exhaust stream were found to be of low fidelity due to heat losses in the exhaust system. The OSU Calorimeter (Smith 1971), an early bench scale test for measuring heat release rate, used this method. Measurements of carbon dioxide and carbon monoxide have also been used with exhaust flow rate measurements to determine heat release rate (Tewarson and Tamanini 1976, Tewarson and Pion 1977). However, the heat release rate per mass of carbon dioxide/carbon monoxide is more dependent on the composition of the fuel than is oxygen consumption, and measuring heat release rate using carbon dioxide and carbon monoxide (and other hydrocarbon measurements) is more complex, expensive and time consuming to perform.

Central to oxygen consumption calorimetry is the empirical observation that the heat released per unit of oxygen consumed is approximately constant (Steckler 2000). Parker (1977) recognized this empirical fact and tabulated the heat release per unit oxygen consumed for 17 fuels. Huggett $(1978,1980)$ made a more rigorous study of the variations in heat release per unit oxygen consumed over a wider range of fuels and over a range of combustion conditions. He recognized that the concept itself had been discovered by Thornton (1917). His work established the heat release per unit oxygen consumed as $13.1 \mathrm{~kJ} / \mathrm{g}$ of oxygen $\pm 5 \%$. Huggett's paper provided a strong foundation for oxygen consumption calorimetry which gave the fire research community the confidence to move forward with developing it as a measurement methodology. The constancy of the heat released per oxygen consumed was also discussed by Babrauskas (1976) in his $\mathrm{PhD}$ work on fully developed compartment fires.

Beyond the constancy of the heat release per unit oxygen consumed there was a need to use this empirical fact to actually measure the heat release rate in fire. This was accomplished first by Parker (1977) in his analysis of the ASTM E84 test method. The work had been done in 1974, but was not published until 1977. There were earlier efforts by Hinkley et al. (1968) and by Christian and Waterman (1971), discussed below, in which the relationship between oxygen depletion in a hooded exhaust was directly related to the heat release rate.

\section{Impact on public safety}

The advent of oxygen consumption calorimetry by Parker (1977) allowed fire research to move forward with confidence. The need for the technology was understood by the research community at least as early as 1959 (Emmons 1959). Finally, there was a straightforward and credible method for measuring the primary metric of a fire, its heat release rate history.
Sensenig and Parker (1978) applied OCC to a NIST bench scale test method. Krause and Gann (1980) applied the OCC method to the OSU Calorimeter. By 1982 the cone calorimeter, a fire test method for characterizing the burning behavior of materials using OCC, had been developed by Babrauskas et al. (1982). By 1985 it was a draft ASTM test method, and by 1990 it was accepted as a full ASTM standard. By 1993, the test method was adopted as an ISO standard.

Heskestad (1981) implemented OCC into a large scale fire products collector (10 MW scale) at Factory Mutual (now FM Global). Heskestad rigorously defined the conditions of collection required for accurate calorimetry. Shortly thereafter, a large OCC-based calorimeter for furniture objects was developed (Babrauskas et al. (1982)). Benchmark heat release rate data was available for the first time (Lawson et al. (1984)), Alpert and Ward (1983)). The data was immediately put to use as input data for simple calculations like FIREFORM and zone fire models like CFAST.

Room fire test methods incorporating OCC began development in 1977 as well (Beason and Alvares (1977), Sensenig (1980)). Both these papers directly cited Parker's 1977 paper on the ASTM E84 test method as the basis and inspiration for their work. Sensenig (1980) also cited Huggett's 1978 paper on the constancy of the heat release per unit oxygen consumed as a further basis of his work. Work by Williamson and Fischer (1979) and Wickström et al. (1983) began the process of standardizing room fire test methods involving OCC.

Oxygen consumption calorimetry is also widely used during fire suppression testing (Walton (1988), Dlugogorski et al. (1994)) where thermal methods are not possible due to heat absorption by the extinguishing agent.

All these efforts were foundational with respect to fire research, quantitative fire protection engineering, and standardized fire test methods. Oxygen consumption calorimeters became widespread in the fire research and testing world. The cone calorimeter design by Babrauskas et al. (1982) and the product fire collector design by Heskestad (1981) became models for the design of calorimeters from bench scale to full scale. The fact that the apparatus required was only an exhaust hood and fan that was required to remove smoke from the lab anyway and instrumentation required included only a flow measurement and oxygen concentration measurement made the OCC approach readily adaptable to a range of measurements and test methods. All this equipment could be installed appropriately in the exhaust system and remain in place for use in all testing using the hood. Smoke obscuration, $\mathrm{CO}, \mathrm{CO}_{2}$ measurements were also typically added. Because the instrumentation was not part of the test setup, but rather was integral to the facility, little test specific work was required. Modern computer-based data 
acquisition equipment resulted in real time output of heat release rate as the test proceeded.

Oxygen consumption calorimetry has become an integral part of many standard fire tests. Janssens (2008) identified the following test methods that use oxygen consumption calorimetry: ASTM E1354, E1537, E1590, E1623, E1822, E2067, E2257, ASTM D7309; FM 4995; ISO 5660, 9705; NFPA 265, 271, 286; NT Fire 032, 16 CFR Part 1633, California TB 603. This list is representative rather than exhaustive, and many other test methods internationally use oxygen consumption calorimetry. Additional tests are continually being developed to incorporate OCC, e.g. IEC 60332 or EN 13823. These range from bench to full scale test methods and include research and regulatory testing. Oxygen consumption calorimetry is used in regulatory testing for materials, for furnishings, and for interior finish.

Oxygen consumption calorimetry has had a significant effect on product $R \& D$ activities. The cone calorimeter is the single most used apparatus for studying new and modified materials, for studying the impact of fire retardants, for developing highly fire-resistant polymers and fire protecting coatings. (Grand (1995)).

Oxygen consumption calorimetry can be applied equally to bench scale test methods to study material flammability (e.g. the Cone Calorimeter) to full scale fire testing of industrial scale fires $(\sim 20 \mathrm{MW})$. Indeed, the MW capacity of a test facility's fire calorimeter is a primary metric of a "large lab". The method has also been used in full scale tunnel fire configurations with heat release rates in excess of $100 \mathrm{MW}$. The heat release rate from full scale fire tests are widely used as inputs to fire models for the assessment of fire hazards.

A key part of the OCC innovation has been the measurement of heat release rate and the fundamental role it plays in so many research efforts and test methods. The data on heat release rate now available to all fire safety engineers globally to incorporate into their fire models for buildings, transport infrastructure and industrial premises, has been fundamental to the design of facilities which have improved fire safety. In addition the development of numerous small and large scale test methods based on OCC has led to a much greater understanding of fundamental material behavior across a very wide range of materials. This has allowed building and fire authorities to better regulate the use of these materials and significantly reduce the fire risk and improve public safety. Oxygen consumption calorimetry has had a significant impact on the regulation and safety of furnishings and interior finish materials.

\section{Significant technical developments and individual contributors}

A DiNenno Prize nomination is expected to be "a single technical development to enhance public safety and its implementation by one or several individuals who made significant contributions to that development".

Technical developments usually evolve from a continuum of work performed by many investigators, inventors and entrepreneurs - each improving on the works of others. While the constancy of heat release rate per unit oxygen was recognized for gases and liquids in the early 20th century outside the fire research community, this concept was recognized and applied in the fire safety field by Dr. William Parker, National Bureau of Standards (NBS) now the National Institute of Standards and Technology (NIST), in 1974. Dr. Parker was a Research Associate at Underwriters Laboratory in 1974, studying the performance of the ASTM E84 tunnel test (Parker 1977). In the abstract of the study, Parker reported:

While oxygen depletion in the tunnel did not appear to be a dominating factor in controlling the flame spread, the oxygen depletion measured in the exhaust duct beyond the tunnel correlated with the total rate of heat production of the specimens.

In the main body of the experimental section he reported:

The decrease in oxygen concentration of the air leaving the tunnel provides an approximate measure of the heat released by the specimen. This is based on the assumption that for a given volume of oxygen consumed there will be a fixed amount of heat released regardless of the type of fuel.

He tabulated the heat produced per volume of oxygen (STP) for 17 different fuels and observed that the value was constant within about $15 \%$. His first recommendation for improvement of the tunnel test was:

\section{It is suggested that an oxygen analyzer could be included in the standard tunnel test. This measurement is not affected by the heat losses in the tunnel, as is the temperature recorded by the fuel contribution thermocouple. However, the mass flow rate into the tunnel must be constant or known.}

The cited NBS heat release rate calorimeter was developed by Parker and Long (1972), to which Sensenig and Parker (1978) later added OCC capability. It was a bench scale calorimeter which included radiative heating of the sample and measured heat release rate by a thermal compensation method whereby a gas burner is varied to maintain a fixed exhaust temperature in the apparatus exhaust such that the heat release rate of the sample is the same as the reduction in the required burner heat release rate. This was a predecessor of the cone calorimeter. 
In 1982, Parker published the detailed methodology and equations required for rigorous implementation of the method in an NBS-IR report. The report provided the methods for applying oxygen consumption calorimetry to various applications (Parker 1982) which was republished in the Journal of Fire Sciences (Parker 1984). The development and publication of the detailed methodology was important to the growth in the use of OCC and the rigor of the methodology enhanced the credibility of the method. The history of oxygen consumption calorimetry and Parker's central role have been chronicled by Lawson (2009) as part of his history of fire testing and as a classic paper review (Lawson 2012). The importance of Parker's innovation is clearly shown by the rapid adoption of oxygen consumption calorimetry in fire research work (see for example Beason and Alvares 1977, Huggett (1980), Sensenig (1980), Babrauskas et al. 1982).

Dr. Clayton Huggett, a colleague of Dr. Parker at NBS, studied the constancy of the heat release per unit oxygen consumed. Both Dr. Huggett and Dr. Parker gave technical papers on oxygen consumption calorimetry at the Eastern States Combustion Institute meeting in 1978. Dr. Huggett's paper focused on the constancy of the heat release per unit oxygen consumed, while Dr. Parker's talk centered on the implementation of the method in a laboratory scale apparatus. The importance of their findings was recognized straightaway and technical papers including oxygen consumption calorimetry began appearing immediately. Dr. Clayton Huggett is deceased and, under the rules of the Charter, is not be eligible to posthumously share the prize with his colleague Dr. William Parker. If he had been alive at the time of the prize he would have been included as co-recipient. The 2016 Philip J. DiNenno Prize was therefore awarded to Dr. William Parker, with ample commendation to Dr. Huggett.

Dr Huggett's principal contribution to oxygen consumption calorimetry was his 1980 paper, "Estimation of Rate of Heat Release by Means of Oxygen Consumption Measurements," published in Fire and Materials. The paper was based upon his 1978 paper presented at the Eastern States Combustion Institute meeting. His papers were the first to recognize Thornton's 1917 paper on the constancy of the heat release per unit oxygen consumed for gaseous and liquid fuels. It was he who thoroughly examined the constancy of the heat release per unit oxygen consumed over a wide range of materials and combustion conditions. His paper is the most widely cited paper with respect to oxygen consumption calorimetry and gave the fire research community the confidence to implement oxygen consumption calorimetry in both their research equipment and in standard fire testing methods.
In addition to the seminal work of Parker and Huggett, there have been many contributors to the development and implementation of oxygen consumption calorimetry. In the preface to Heat Release in Fire edited by Babrauskas and Grayson (1992), the editors state:

The development of heat release rate (HRR) study as an aspect of fire protection engineering has been one of the salient triumphs of the profession during the 1980s. William J. Parker and Clayton Huggett re-discovered the long-obscure principle of oxygen consumption in the late 1970s. Efforts to measure and to use HRR were being carried out prior to that time, but without significant success or penetration into mainstream fire protection engineering. This re-discovery, and the detailed instructions published by Parker on how to carry out computation, changed the situation drastically. It was realized that such HRR measurements provide the very cornerstone of fire protection engineering by quantifying the answer to the question: How big is the fire?

Peter Hinkley, Fire Research Station, Borehamwood UK Peter Hinkley recognized in 1968 that in his wood crib burning tests, there was a correlation between the heat release rate and the oxygen depletion in the hood exhaust (Hinkley et al. 1968). He recognized the potential of the method in that it did not suffer from lags and losses associated with direct thermal methods. He did not explore the generality or accuracy of the method in any detail and did not follow up on his findings.

William Christian and Thomas Waterman, Illinois Institute of Technology Research Institute

They published a paper in Fire Technology (Christian and Waterman 1971) that made use of the oxygen deficiency in the exit flow to estimate heat release rate in a room/corridor fire experimental program. They calibrated their system using propane on the assumption that the heat release rate per unit oxygen consumed was constant. They reported:

\section{It was found that there was essentially a linear relation between heat release rate and airflow rate for these fires, and it was assumed that this relationship applied to all of the fires with real fuel loadings as well. For this assumption to be valid, all of the fires must be equally efficient in using the oxygen available, and the heat release per unit mass of oxygen consumed must be the same for all of the fuels.}

Christian and Waterman did not follow up on their findings and did not identify their oxygen consumption findings in the conclusion of their paper.

Darryl L. Sensenig, Armstrong Cork Company, NBS Research Associate 
As a research associate at NBS, Sensenig worked with Parker in the development of a bench scale calorimeter using the oxygen consumption principle (Sensenig and Parker 1978). He went on to develop a $1 / 4$ scale and full scale room test for interior finish materials using the oxygen consumption principle (Sensenig 1980).

\section{Ralph Krause and Dr. Richard Gann, NBS}

Researchers at NBS, Ralph Krause and Dr. Richard Gann applied the oxygen consumption calorimetry method to the OSU calorimeter (Krause and Gann (1980). Their work indicated definite improvements in time response of the OSU apparatus and showed resilience with respect to the relative magnitude of convective vs radiative output of the fire. They cited Huggett's 1980 paper as well as Parker (1977) and Sensenig and Parker (1978).

Dr. Vyto Babrauskas, Formerly NBS, Fire Science and Technology Inc

While Parker invented oxygen consumption calorimetry as an experimental method, moving the technology into standard test methods was an important part of enhancing its reach, importance, and influence. At NBS, Babrauskas developed the cone calorimeter which incorporated the new oxygen consumption calorimetry and moved it through adoption as an ASTM test method. By 1986 a draft ASTM test method had been developed and test method was formally issued as ASTM E1354 in 1990 (Babrauskas 1995). It was accepted as a draft ISO standard in 1990 and issued in 1993. By 1995, over 100 cone calorimeters were in use world-wide. In 1988 the cone calorimeter was awarded the R\&D 100 Award, the first fire test method ever so recognized as a technological innovation. Babrauskas also had a role in the development of the furniture calorimeter using the oxygen consumption principle (Babrauskas et al. (1982)). Babrauskas and Grayson (1992) edited a book, Heat Release in Fires, which pulled together the theory, development, and application of oxygen consumption calorimetry. It has recently been reprinted and continues to be an important reference work. It is of note that Babrauskas in his study of fully developed compartment fires as part of his thesis work at UC Berkeley had recognized the constancy of the heat release per unit oxygen consumed (Babrauskas 1976).

Dr. Gunnar Heskestad, Factory Mutual Research Corp.

Heskestad developed the first design of a large scale calorimeter using the oxygen consumption calorimetry method (Heskestad (1981)). His detailed design has been the basis for implementation of accurate fire calorimetry, including the use of oxygen consumption calorimetry in laboratories around the globe. He explored the conditions required to make accurate measurements, contributing to the credibility of the technique.
Norm Alvares, Donald Beason, Lawrence Livermore Laboratory, University of California

Beason and Alvares (1977) published a paper on the application of oxygen consumption calorimetry in a compartment in the same year as Parker's analysis of the E-84 test. They clearly attribute the method to Parker's E-84 paper. They were the first of the many early adopters, illustrating the clear importance of the invention.

Dr. R. Brady Williamson, University of California, Berkeley

Under a grant from NBS, monitored by Bill Parker, Williamson (Williamson and Fischer 1979) developed a room fire test standard for the evaluation of interior finish materials that ultimately resulted in the UBC 42-2, Standard Test Method for Evaluating Room Fire Growth contribution of Textile Wall Covering (also now NFPA 265).

As this summary of early contributors to the development and adoption of OCC shows, the innovation centered on a group of researchers at NBS with important contributions from researchers around the world. The work at NBS was under the leadership of Dr. John Lyons, the Director of the Center for Fire Research. A summary of the research at NBS in that period is included in a history of fire research at NBS (Wright 2003).

\section{Summary}

The 2016 DiNenno Prize recognizes oxygen consumption calorimetry as a significant technical achievement that has had a major impact on public safety. Oxygen consumption calorimetry has made the measurement of heat release rate of a fire a routine part of fire testing for both research and for regulatory compliance. Heat release rate is a primary metric of fire size which is foundational in modern fire protection engineering. The 2016 Philip J. DiNenno Prize is awarded to Dr. William Parker, with ample commendation to his deceased collaborator, Dr. Clayton Huggett. Others who made contributions to the early development and application of oxygen consumption calorimetry include Peter Hinkley, William Christian, Thomas Waterman, Darryl Sensenig, Ralph Krause, Richard Gann, Vyto Babrauskas, Gunnar Heskestad, Norm Alvares, Donald Beason, and Brady Williamson.

\section{Timeline}

1917- Thornton established constancy of heat release per unit oxygen consumed for gas and liquid fuels

1959- Emmons recognized the need for reliable HRR measurements

1959- Thompson and Cousins used substitution method for calorimetry

1969- Hinkley, Wraight, and Wadley recognized correlation of oxygen depletion with mass loss in experiments 
1971- Christian and Waterman use oxygen depletion to estimate HRR in room fire test

1971- Smith uses sensible heat method in OSU calorimeter

1971- Parker and Long NBS Calorimeter based upon sensible heat substitution

1976- Babrauskas recognized constancy of heat release per unit oxygen consumed

1976- Tewarson and Tamanini implement $\mathrm{CO}_{2}$ based HRR in flammability apparatus

1977- Parker used OCC to determine heat release rate in E84 test method

1977- Beason and Alvares apply Parker's work to room fire test

1977- Tewarson and Pion used $\mathrm{CO}$ and $\mathrm{CO}_{2}$ to determine HRR

1978- Sensenig and Parker report OCC in a bench scale test Eastern States Combustion Institute

1978- Huggett reports OCC method basis at Eastern States Combustion Institute

1979- Fisher and Williamson report room calorimetry measurements for standard test development

1980- Huggett established Thornton's rule for solid fuels in archival literature

1980- Gann and Kraus used OCC in OSU apparatus

1980- Sensenig published room fire OCC method

1981- Parker published calorimeter equations

1981- Heskestad used OCC in large scale hood design (fire products collector)

1982- Babaruskas, Lawson, Walton, and Twilley publish first furniture calorimeter data

1982- Babrauskas published cone calorimeter design

1983- Alpert and Ward publish industrial calorimeter data

1984- Wickström, Sundstrom, and Holmstedt develop full-scale room fire test

1984- Lawson, Walton, and Twilley publish furnishings calorimeter data

1987- NT Fire 032- first published furniture calorimetry standard

1988- Walton applied OCC during suppression

1990- Cone calorimeter accepted as ASTM standard

1992- Babrauskas and Grayson edit volume on HRR in

Fire, based upon OCC methodology

1993- Cone calorimeter accepted as ISO standard

1993- ISO 9705 Room Test with OCC

\section{Authors' contributions}

CB produced an initial draft of this paper. PC, CD, PJ, MM provided additional sources, providededitting to the paper to enhance its historical accuracy, context, and clarity. All authors read and approved thefinal manuscript.

\section{Competing interests}

The authors declare that they have no competing interests.

\section{Author details}

'Jensen Hughes, Baltimore, MD 21227, USA. Factory Mutual Emeritus, Norwood, MA 02062, USA. ${ }^{3}$ National Fire Protection Association, Quincy, MA 02169, USA. ${ }^{4}$ Arup, Melbourne, VIC 3002, Australia. ${ }^{5}$ SP Swedish National Technical Research Institute, Borås, SE -501 15, Sweden.

Received: 3 September 2016 Accepted: 13 December 2016

Published online: 14 January 2017

\section{References}

Alpert R, Ward E (1983) Evaluating Unsprinklered Fire Hazards, SFPE Technology Report 83-2, SFPE

Beason and Alvares (1977), Variations in the Burning Characteristics of Low Porosity Cribs, Lawrence Livermore Laboratory, Western States Section Combustion Institute, Pittsburgh

Babrauskas V (1976) Fire Endurance in Buildings, Report UCB FRG 76-16, University of California Berkeley Fire Research Group, Berkeley

Babrauskas V, Lawson J, Walton W, Twilley W (1982), Upholstered Furniture Heat Release Rats Measured with a Furniture Calorimeter, NBSIR 82-2604, National Bureau of Standards, Gaithersburg

Babrauskas V (1995) The Development and Evolution of the Cone Calorimeter: A Review of 12 Years of Research and Standardization, Fire Standards in the International Marketplace, ASTM STP 1163, ASTM

Babrauskas V, Grayson S (eds) (1992) Heat Release in Fire. Elsevier Applied Science, London and New York

Christian W, Waterman T (1971) Characteristics of Full-Scale Fires in Various Occupancies. Fire Technol 7:205-217

Dlugogorski BZ, Mawhinney JR, Huu Duc V (1994) The Measurement of Heat Release Rates by Oxygen Consumption Calorimetry in Fires under Suppression. Fire Safety Science 4:877-888. doi:10.3801/IAFSS.FSS.4-877

Emmons H (1959) A US Program of Fire Research, NFPA Quarterly, pp 221-223

Grand A (1995) The Influence of Fire Calorimetry Results on Product Research and Development Activities, 50th Calorimetry Conference, NIST

Heskestad G (1981) A Fire Products Collector for Calorimetry into the MW Range, FMRC J. I. OC2E1.RA. Factory Mutual Research Corp, Norwood

Hinkley P, Wraight H, Wadley A (1968) Rates of Heat Outputy and Heat Transfer in the Fire Propagation Test, Fire Research Note 709. Fire Research Station, Borehamwood

Huggett C (1978) Oxygen consumption calorimetry. Fall Technical Meeting on Chemical and Physical Processes in Combustion. Combustion Institute/ Eastern States Section, Pittsburgh

Huggett C (1980) Estimation of Rate of Heat Release by Means of Oxygen Consumption Measurements. Fire Mater 4:61-65

Janssens M (2008) Calorimetry, Section 3, Chapter 2, SFPE Handbook of Fire Protection Engineering. NFPA, Quincy

Krause R, Gann R, (1980) Rate of Heat Release Measurements Using Oxygen Consumption. J Fire Flammability 12: 117- 130.

Lawson J (2009) A History of Fire Testing, NIST Technical Note 1628, National Institute for Standards and Technology

Lawson J (2012) SFPE Classic Paper Review: A Review of the Classic Work by Dr. William Parker on Heat Release Rate Measurements by Oxygen Consumption. J Fire Prot Eng 22:5-9

Lawson JR, Walton WD, Twilley WH (1984) "Fire Performance of Furnishings as Measured in the NBS Furniture Calorimeter, Part 1", NBSIR 83-2787. National Bureau of Standards, Gaithersburg

Parker W (1977) An Investigation of the Fire Environment in the ASTME-84 Tunnel Test, NBS Technical Note 945. National Bureau of Standards

Parker W (1984), Calculations of the Heat Release Rate by Oxygen Consumption for Various Applications. J Fire Sciences 2:380-395.

Parker W (1982) Calculations of the Heat Release Rate by Oxygen Consumption for Various Applications. National Bureau of Standards, Gaithersburg MD. NBSIR 81-242

Parker W, Long M. (1972), Development of a Heat Release Rate Calorimeter at NBS, Ignition, Heat Release, and Noncombustibility of Materials, ASTM STP 502, ASTM, pp 135-151

Sensenig DL, Parker WJ (1978) New Concept for Rate of Heat Release Measurements by Oxygen Consumption. The Combustion Institute/Eastern Section, Pittsburgh

Sensenig D (1980) An Oxygen Consumption Technique for Determining the Contribution of Interior Wall Finishes to Room Fires, NBS Technical Note 1128, National Bureau of Standards 
Smith EE (1971) "Heat Release Rate of Building Materials", STP502. American Society for Testing and Materials, Philadelphia

Steckler K. (2000), Estimation of Rate of Heat Release by Means of Oxygen Consumption Measurements, A Chronicle of Selected NBS/NIST Publications, 1901-2000, NIST Special Publication 958

Tewarson A, Tamanini F (1976) Research and Development for a Laboratory-Scale Flammability Test Method for Cellular Plastics, FNRC Serial No 22524, for the Products Research Committee

Tewarson A, Pion R (1977) A Laboratory Scale Test Method for the Measurement of Flammability Parameters, Factory Mutual Research, Products Research Committee Report, Grant RP 75-1-33A

Thompson N., Cousins E (1959) The FM Construction Materials Calorimeter, NFPA Quarterly, pp 186-192

Thornton WM (1917) The Relation of Oxygen to the Heat of Combustion of Organic Compounds. Philosophical Magazine 33:196-203

Walton WD (1988) Suppression of Wood Crib Fires with Sprinkler Sprays: Test Results. NBSIR 88-3696:1-29

Wickström U, Sundstrom B, Holmstedt G (1983) The Development of a Full-scale Room Fire Test. Fire Saf J 5:191-197

Williamson RB, Fischer F (1979) Fire growth experiments - toward a standard room fire test, WSS-79-48, Department of Civil Engineering and Lawrence Berkeley Laboratory. University of California, Berkeley

Wright R (2003) Building and Fire Research at NBS/NIST 1975-2000, NIST BSS 179

\section{Submit your manuscript to a SpringerOpen ${ }^{\circ}$ journal and benefit from:}

- Convenient online submission

- Rigorous peer review

- Immediate publication on acceptance

- Open access: articles freely available online

- High visibility within the field

- Retaining the copyright to your article

Submit your next manuscript at $\boldsymbol{s p r i n g e r o p e n . c o m ~}$ 